\title{
Article \\ Opening Doors or Slamming Them Shut? Online Learning Practices and Students with Disabilities
}

\author{
Sheryl Burgstahler \\ Accessible Technology Services, University of Washington, Seattle, WA 98195, USA; E-Mail: sherylb@uw.edu
}

Submitted: 8 August 2015 | In Revised Form: 9 December 2015 | Accepted: 17 December 2015 |

Published: 28 December 2015

\begin{abstract}
Online learning has the potential to open doors to education for everyone who has access to the technology required to participate. Or does it? When it comes to social inclusion in online learning, who are the "haves" and who are the "have-nots?" Some online learning practices erect barriers to individuals with disabilities-uncaptioned videos are not accessible to students who are deaf, content presented only within graphic images is not accessible to individuals who are blind, unorganized content cluttered on a page creates barriers to some students with learning disabilities and attention deficits, web pages that require the use of a mouse are inaccessible to those who cannot operate a mouse. This article explores the question, "What online learning practices make social inclusion possible for individuals with disabilities?" The author answers this question with lessons learned from her own teaching experiences as well as those presented in research and practice literature. She also shares overall characteristics of distance learning programs that promote the social inclusion of students with disabilities in their courses. The author points out how making courses welcoming to, accessible to, and usable by individuals with disabilities may promote the social inclusion of other students as well. She recommends further dissemination and future research regarding inclusive practices in online learning.
\end{abstract}

\section{Keywords}

disabled students; inclusive learning; online learning; social inclusion; technologies

\section{Issue}

This article is part of the special issue "Inclusive Technologies and Learning", edited by Don Passey (Department of Educational Research, Lancaster University, UK).

(C) 2015 by the author; licensee Cogitatio (Lisbon, Portugal). This article is licensed under a Creative Commons Attribution 4.0 International License (CC BY).

\section{Introduction}

Online learning opens doors to education for everyone who has access to the technology required to participate. Or does it? When it comes to social inclusion in online learning, who are the "haves" and who are the "have-nots?" In some places, such as many postsecondary campuses worldwide, the availability of information technology (IT) places everyone in the institution on the right side of what has been called the "digital divide." However, even there some faculty and students find themselves on the wrong side of the "second digital divide":

This line separates people who can make full use of today's technological tools, services and resources from those who cannot....People with disabilities who are on the right side of the first digital divide, too often find themselves on the wrong side of the second digital divide. They have technology but do not have full access to all of the benefits it delivers to others. (Burgstahler, 2005, p. 84)

Inclusive practices in online learning (otherwise called e-learning or distance learning) that support social inclusion can be informed by five cornerstones for promoting social inclusion: (1) valued recognition, (2) human development, (3) involvement and engagement, (4) proximity, and (5) material well-being (Donnelly \& Coakley, 2002). Applying this model to inclusive online 
learning, valued recognition requires the acknowledgment and respect of individual and group characteristics. Human development requires the encouragement of diverse capabilities, skills, and perspectives and recognition of them as worthwhile. Involvement and engagement requires that students receive the necessary support to be fully engaged in all aspects of a course. Proximity ensures the opportunity for students of all backgrounds and abilities to interact in the shared social space of a course. Material well-being requires that potential students have the resources necessary to fully participate in an online course. Donnelly and Coakley (2002) make a clear distinction between inclusive programming and programming that promotes social inclusion and/or integration. Simply being enrolled in an online learning class does not mean that a student is fully included. Ensuring that all students are fully included requires the instructor to take intentional steps, some summarized in the remainder of this article, that ensure a welcoming and accessible environment for students with a broad range of characteristics, including disabilities.

Some online learning practices erect barriers to individuals with disabilities. Uncaptioned videos are not accessible to students who are deaf. Content provided only within a graphic image (without an alternative description in a text-based format) is not accessible to screen readers that are used by individuals who are blind, since this technology can only read aloud content formatted as text. Even text-based content in a document or on a web page can be tedious to access for these students when the headings are not structured because their screen readers can only skim through heading text if it is formatted as a heading. In addition, since a screen reader can skip from link text to link text to determine resources they wish to access, links to online resources that are not descriptive of the resource (e.g., "click here" is routinely used instead of a description of the content they will find if they click on that link) do not help in this process; blind students are required to link to each resource to determine what it is. Unorganized content cluttered on a page creates barriers to some students with attention deficits or learning and other disabilities. Web pages that require the use of a mouse are inaccessible to those who cannot operate a mouse or other product with mouse functionality.

This article explores the question, "What online learning practices make social inclusion possible for individuals with disabilities?" The author shares suggestions presented in the literature as well as lessons learned from her own teaching. The article includes recommendations for practices that promote the social inclusion of students with disabilities in online learning programs as a whole and in an individual course. The author points out how making courses welcoming to, accessible to, and usable by individuals with disabilities benefits oth- ers as well, thus laying the foundation for the social inclusion of all potential students. She also recommends future research and dissemination in the field.

\section{Approaches to Access: Accommodations and Universal Design (UD)}

Today, it is possible for assistive technology to allow individuals with almost any types of disabilities to operate computers (Closing the Gap, 2015). These products include screen readers for individuals who are blind or who have reading-related disabilities, alternative keyboards and mice for people who have mobility impairments, and assistive software for students with learning disabilities. Worldwide, many people do not have access to these technologies. However, online courses can erect barriers even to students who have access to computers and the assistive technologies they need (National Council on Disability, 2004). For example, screen reader software with speech synthesis reads aloud text that appears on the screen and, thus, provides access to only the content of online resources that are available in text formats. Therefore, online learning designers and instructors can avoid erecting barriers to students who are blind and have access to text-to-speech technology by providing text alternatives such as <alt> tags to fully describe the content presented in graphic images. Similarly, structured textonly versions of documents in Adobe Portable Document Format (PDF) are accessible to individuals who are blind.

Employing multiple and flexible teaching methods to reach students with a wide range of characteristics fosters the academic and social growth of all students (Gurin, Dey, Hurtado, \& Gurin, 2002), including those with disabilities (Silver, Bourke, \& Strehorn, 1998). Often mentioned in this regard are teaching practices that include cooperative learning, contextual learning, constructive learning, the provision of organizing tools, multimodal instruction, peer editing, and testing in the same manner as teaching.

"Universal design" (UD)-and similar approaches labeled with other names such as "design for all" or "inclusive design"-has emerged over the last two decades as a framework for describing a proactive, fully inclusive model for all aspects of instruction. UD has a rich history in a wide range of applications. Architects, product designers, engineers, and environmental design specialists at the Center for Universal Design (CUD) established seven principles of UD to provide guidance in designing products and environments to be usable by all people, to the greatest extent possible (CUD, 1997). Researchers and practitioners have applied these principles to specific products, practices, and environments. In all applications of UD to teaching, instructors anticipate the presence of students with diverse abilities and other characteristics, and make design deci- 
sions that result in learning opportunities available to all of these individuals, rather than focusing only on the average or "typical" student (Burgstahler, 2015a). Thus, universally designed courses are welcoming to, accessible to, and usable by all potential students.

IT is well suited to delivering the multiple presentation options characteristic of UD. In 1995 the author of this article co-taught the first online course offered through the University of Washington (UW) distance learning program. It is described below.

The course presented an overview of assistive technology for people with disabilities. She and her co-instructor, Professor Norm Coombs at the Rochester Institute of Technology, who happens to be blind, set out to make the content and interactions fully accessible to anyone with a disability who might enroll in our course. A series of DO-IT [Disabilities, Opportunities, Internetworking, and Technology] videos that were both captioned and audio described and presented in Video Home System (VHS) format were mailed to the students. Electronic mail and a text-based listserv distribution list were used for communication. There was no world wide web, but a gopher server developed at the University of Minnesota was used to organize textbased course materials. Other online resources were accessed through Telnet and File Transfer protocols. When the instructors were asked if students with disabilities were enrolled in course offerings they were proud to say that they did not know. There was no need to disclose a disability when all of the materials and communications were in accessible formats. Dr. Coombs disclosed his blindness, but only because of its relevance to the course content. (Burgstahler, 2015a, pp. 49-50)

The years since this course was taught have witnessed tremendous increases in the number of technologies used in online courses, in the number of online courses available, and in the number of students taking these courses (Allen \& Seaman, 2009; Kim-Rupnow, Dowrick, \& Burke, 2001; Kinash, Crichton, \& Kim-Rupnow, 2004; Phillips, Terras, Swinney, \& Schneweis, 2013). The rapid pace at which new technologies are introduced make accessibility issues both more complex and more important to address. However, the basic issues remain the same-pedagogical and technical issues must be addressed in order for courses to be welcoming to, accessible to, and usable by all students. For example, access barriers can emerge when the learning management system (LMS) that delivers the content and engagement options includes inaccessible features. In addition, teaching methods used by online instructors and the IT they employ (e.g., videos) can erect barriers to some students. Ideally, a universally designed course would support a student's preferred access methods (e.g., speech input, alternative keyboard, the keyboard alone) and output preferences (audio text, graphical, video), and be customizable.

Online instructors and institutions tend to employ an accommodations-only model rather than a proactive model in dealing with accessibility (Barnard-Brak \& Sulak, 2010; Kim-Rupnow et al., 2001; Kinash et al., 2004; Seale, 2014a). The accommodation-only approach problematizes individual deficits rather than addressing inequalities that result from the inaccessible design of the course. UD at its best promotes a culture of diversity that celebrates individual differences. Being both proactive (by applying universal design principles) and reactive (by being ready to provide accommodations to individual students when needed) is the ideal when it comes to social inclusion in the online world.

\section{Guidelines for Inclusive Online Courses}

Accessibility has been addressed in general standards for high quality online learning. For example, the International Association for K-12 Online Learning (2011) published standards for quality online courses that include accessible design recommendations for both technology and learning activities. In addition, the Quality Matters Rubric for high quality e-learning courses includes accessibility and usability as the eighth benchmark and recommends that this benchmark be applied to the other seven-course overview and introduction, learning objectives (competencies), assessment and measurement, instructional materials, course activities and learning interaction and engagement, course technology, and learner support (Quality Matters, n.d.). With respect to accessibility, many online learning guidelines point to the work of the World Wide Web Consortium (W3C). W3C is the organization that develops and maintains protocols to ensure interoperability of the web world-wide. It has always been committed to UD. According to Tim Berners-Lee, the inventor of the web, "The power of the Web is in its universality. Access by everyone regardless of disability is an essential aspect" (BernersLee, n.d.). Consistent with its vision of a fully inclusive environment, in 1997 W3C introduced a Web Accessibility Initiative (WAI) to develop guidelines for the accessible design of websites. The WAI recognizes that

web accessibility also benefits people without disabilities. For example, a key principle of web accessibility is designing websites and software that are flexible to meet different user needs, preferences, and situations. This flexibility also benefits people without disabilities in certain situations, such as people using a slow Internet connection, people with "temporary disabilities" such as a broken arm, and people with changing abilities due to aging. (WAI, n.d.-c, What is Web Accessibility section) 
In 1999, the Web Content Accessibility Guidelines 1.0 (WCAG 1.0), with input from a wide variety of stakeholders worldwide, were published as a W3C recommendation (2003). Now WCAG 2.0 is widely regarded as the current international standard for web accessibility. The WAI guidelines make it possible to objectively measure whether web pages are accessible, and many software tools have been developed for checking or validating content for accessibility. WCAG 2.0 includes recommendations for making web content accessible to people with a wide range of disabilities that include blindness and low vision, deafness and hearing loss, learning disabilities, cognitive limitations, limited movement, speech difficulties, photosensitivity, and combinations of these. The guidelines are organized around four principles (WAl, n.d.-b, Understanding the Four Principles of Accessibility section) to ensure that web content is

- Perceivable-Information and user interface components must be presentable to users in ways they can perceive.

- Operable-User interface components and navigation must be operable.

- Understandable-Information and the operation of user interface components must be understandable.

- Robust-Content must be robust enough that it can be interpreted reliably by a wide variety of user agents, including assistive technologies.

Making the web accessible to people with disabilities requires that different components of IT and user involvement work together. These components include web content in text, images, and sounds, as well as markup that defines the structure and presentation; user agents such as web browsers and media players; assistive technology such as screen readers and alternative keyboards; user knowledge, skills, and adaptive strategies for using the web; developers, designers, coders, and authors, including those with disabilities; authoring tools used to create websites; and evaluation tools such as web accessibility evaluation tools and HyperText Markup Language (HTML) validators.

WAI (n.d.-a, Table of Contents section) offers the following quick tips for ensuring web accessibility:

1.1 Text alternatives. Provide text alternatives for any non-text content so that it can be changed into other forms people need, such as large print, braille, speech, symbols, or simpler language.

1.2 Time-based media. Provide alternatives for time-based media.

1.3 Adaptable. Create content that can be presented in different ways (for example, simpler layout) without losing information or structure.
1.4 Distinguishable. Make it easier for users to see and hear content, including separating foreground from background.

2.1 Keyboard accessible. Make all functionality available from a keyboard.

2.2 Enough time. Provide users enough time to read and use content.

2.3 [Medical] Seizures. Do not design content in a way that is known to cause seizures. (e.g., avoid flashing images)

2.4 Navigable. Provide ways to help users navigate, find content, and determine where they are.

3.1 Readable. Make text content readable and understandable.

3.2 Predictable. Make web pages appear and operate in predictable ways.

3.3 Input assistance. Help users avoid and correct mistakes.

4.1 Compatible. Maximize compatibility with current and future user agents, including assistive technologies.

WAI guidelines are updated regularly. They are general enough that they stand the test of time, applying to new technologies as they are developed. In addition to WCAG, individual countries have developed standards for web accessibility (e.g., the British Standard BS 8878; British Standards Institute, 2010).

\section{Guidelines for Program-Level Inclusive Practices}

There are many ways to justify making social inclusion of students with disabilities an important issue for online learning program administrators to address. They include: (1) many people consider it unethical to bar some eligible participants from program access; (2) applying accessible design principles is a best practice for all students; (3) costly redesign may be required when a student with a disability enrolls in an inaccessible course; and (4) legislation in some countries mandates that programs be accessible to qualified people with disabilities. Even the Convention on the Rights of Persons with Disabilities of the United Nations (2006) states as a purpose to ensure that people with disabilities have access, on an equal basis with others, to information and communications, including information and communications technologies and systems.

How UD can be integrated into the practices of online learning programs as a whole is not widely addressed in the literature. However a set of guidelines for distance learning programs was created as a product of a study conducted by the DO-IT Center at the University of Washington in Seattle (Burgstahler, Corrigan, \& McCarter, 2005) and disseminated through DO-IT's Center for Universal Design in Education (DO-IT, n.d.-a).

The exploratory study addressed the research question: What are program-level policies and practices re- 
lated to delivering online courses that are fully accessible to students with disabilities? Building on lessons learned in early work in this area (Burgstahler, 2002; Burgstahler, Corrigan, \& McCarter, 2004), a draft of an initial list of Distance Learning Program Accessibility Indicators (DLP Accessibility Indicators) was created. It was designed to be used as a checklist of programmatic characteristics that can ultimately lead to more inclusive courses in any online learning program. The study engaged online learning programs at institutions whose disabled student service directors were part of projects funded by the United States Department of Education (grant \#P333A020044 and \#P333A990042) and directed by the DO-IT Center. These projects focused on training faculty and staff at postsecondary institutions to more effectively include students with disabilities in their courses and service offerings. Of the twenty-three schools initially considered for the distance learning project, eighteen had online learning programs that offered courses at a distance and in multiple academic areas. Online learning administrators of two of these eighteen schools declined to participate in the study, resulting in an $89 \%$ participation rate.

A wide range of institutional characteristics was represented in the sixteen participating schools-large and small schools; two-year (5) and four-year institutions (11); and schools from rural, suburban, and urban areas. A DO-IT staff person contacted online learning administrators at the participating schools. She shared the draft DLP Accessibility Indicators, web resources, and DO-IT publications and training videos to increase participant awareness of accessibility issues and solutions; encouraged them to join an electronic discussion group, AccessDL, focused on the accessible design of distance learning; collected examples of each Indicator applied at institutions as models for participants to consider; performed accessibility reviews of program web pages and offered suggestions for improvements; encouraged participants to adopt the Indicators at their schools; and helped develop a resource website, AccessDL (DO-IT, n.d.-c).

The DLP Accessibility Indicators were refined through formative feedback from participants in an iterative process that resulted in the list shared in the paragraphs that follow. (Burgstahler, 2006, p. 86, 2012, p. 3). It is organized by relevant stakeholder group.

\section{For Students and Potential Students}

Distance learning programs committed to accessibility assure that students and potential students know of the programs' commitment to accessible design, how to report inaccessible design features they discover, how to request accommodations, and how to obtain alternate formats of printed materials; the distance learning home page and all online and other course materials of distance learning courses are accessible to individuals with disabilities.
- DLP Accessibility Indicator 1: The distance learning home page is accessible to individuals with disabilities (e.g., it adheres to Section 508, World Wide Web Consortium, or institutional accessibledesign guidelines/standards).

- DLP Accessibility Indicator 2: A statement about the distance learning program's commitment to accessible design for all potential students, including those with disabilities, is included prominently in appropriate publications and websites, along with contact information for reporting inaccessible design features.

- DLP Accessibility Indicator 3: A statement about how distance learning students with disabilities can request accommodations is included in appropriate publications and web pages.

- DLP Accessibility Indicator 4: A statement about how people can obtain alternate formats of printed materials is included in publications.

- DLP Accessibility Indicator 5: The online and other course materials of distance learning courses are accessible to individuals with disabilities.

\section{For Distance Learning Designers}

- DLP Accessibility Indicator 6: Publications and web pages for distance learning course designers include: (a) a statement of the program's commitment to accessibility, (b)

guidelines/standards regarding accessibility, and (c) resources.

- DLP Accessibility Indicator 7: Accessibility issues are covered in regular course designer training.

\section{For Distance Learning Instructors}

- DLP Accessibility Indicator 8: Publications and web pages for distance learning instructors include (a) a statement of the distance learning program's commitment to accessibility, (b)

guidelines/standards regarding accessibility, and (c) resources.

- DLP Accessibility Indicator 9: Accessibility issues are covered in training sessions for instructors.

\section{For Program Evaluators}

- Accessibility Indicator 10: A system is in place to monitor the accessibility of courses, and, on the basis of this evaluation, the program takes actions to improve the accessibility of specific courses and to update information and training given to potential students, students, course designers, and instructors.

An average of only 3.3 (33\%) of the ten Indicators were already implemented to some degree at participating schools as the project began. These findings are consistent with literature that concludes that students 
with disabilities are rarely considered in the design of distance learning courses (Kinash et al., 2004). At the beginning of this study the sixteen participating schools had implemented a total of forty-eight Indicators, at least partially, representing an average of 3 per school; by the end of the study, they had implemented or partially implemented a total of sixty-six Indicators, an average of 4.1 per school. In addition, some participants took steps that did not represent enough improvements to change an Indicator from "no" to "some" or "yes." It should be noted that changes made at three schools accounted for 14 (78\%) of the changes overall.

The idea of accessibility, once understood, was enthusiastically received by most of the distance learning staff engaged in the study, but change was slow. These findings are consistent with literature that has for many years concluded that systemic change is often a slow process (Bruce \& Wyman, 1998; Guy, Reiff, \& Oliver, 1998). Reports from participants suggest increases in awareness, interest, and skills that may lead to ongoing, systemic changes in the distance learning programs they represented. In many cases, project engagement opened or increased communications between staff from disability services, distance learning programs, and computing services. Lack of time to address accessibility issues and the need to work with other staff were the most commonly reported reasons for not implementing changes. More research is needed to study how online learning programs can employ practices that ensure the social inclusion of students and instructors with disabilities in all course offerings.

\section{The Current State of the Accessibility of Online Learning Courses}

Many e-learning courses unintentionally erect access barriers that can have a negative effect on the social inclusion of students with disabilities (Burgstahler, 2002, 2006, 2007, 2015b; Coombs, 2010; Fichten et al., 2009; Keeler \& Horney, 2007; Kim-Rupnow, Dowrick, \& Burke, 2001; National Council on Disability, 2004; Thomson, Fichten, Havel, Budd, \& Asuncion, 2015). Inaccessible features of these courses that students with disabilities report include uncaptioned videos, disorganized content and presentations, and PDF files and other course documents that cannot be read by screen readers (Gladhart, 2010). In one study, close to $70 \%$ of students with disabilities had not disclosed their disabilities to their online instructors (Roberts, Crittenden, \& Crittenden, 2011). Almost half of the respondents said that they perceived their disabilities to have a negative impact on their ability to succeed in an online course. In another study female students with learning disabilities who enrolled in online courses reported that the learning environments of these courses were less supportive and less satisfactory than females who did not have learning disabilities (Heiman, 2008).
Some designers are unaware of accessibility issues; some are aware but place a very low priority on employing accessible practices; others consider the market for accessible courses to be too small to address. One study concluded that

People with disabilities want to use the same products that everyone else uses. Implementation of universal design satisfies this desire of people with disabilities, while also providing more cost-effective products for all users. While it is impossible to satisfy the needs of all users, products and services that come closer to accommodating a variety of physical and cognitive differences will benefit both users and companies. (National Council on Disability, 2004, p. 20)

Many strategies for making online learning accessible to students with disabilities are reported in the literature (e.g., Burgstahler, 2015b; Coombs, 2010; Fichten et al., 2009; Keeler \& Horney, 2007; Pearson \& Koppi, 2006; Rangin, 2011; Savidis \& Stephanidis, 2005; Seale, 2014a). For example, to get started in designing an accessible online course, DO-IT (n.d.-b, p. 1) has suggested that first steps include:

- Include a statement on the syllabus about how to request a disability-related accommodation and how to report a design feature of the course that is not accessible.

- Make learning objectives, expectations, assignments and due dates, grading rubrics, assessment questions, and other course elements clear.

- Use consistent and predictable screen layouts and single columns when possible.

- Structure lesson pages and documents using the heading feature of the product you are using (e.g., Microsoft Word, PDF).

- Make sure the text of links is descriptive of the resource linked to rather than use wording like "click here".

- Make sure that color is not the only way to convey important information and make background screens plain and with high contrast to text.

- Share definitions of terms that might be unknown to some students.

- Provide alternative text to describe important content presented in images.

- Caption videos or, when not possible to do so, provide transcriptions.

- Design HTML, Microsoft Word, Microsoft PowerPoint, and PDF documents in accessible formats.

Online learning researchers and practitioners offer these questions to be addressed by online instructors 
(Thomson, Fichten, Havel, Budd, \& Asuncion, 2015, pp. 282-283):

1. Has careful thought been given to the diversity of learners in the course? Are there barriers in any area of the course for learners with different abilities (e.g., artistic, numerical), circumstances (e.g., English language learners), concerns (e.g., finances) and disabilities (e.g. visual impairment)?

2. Has the accessibility of the LMS, including its various components, been considered for all persons, including those with different disabilities (for example, are the calendar, announcements, discussion board, chat, and quizzes accessible, can students easily distinguish new discussion threads, does the announcements tool indicate the number of new announcements posted)?

3. Has consideration been given to the variety of platforms and mobile devices students could be using to interact with the e-learning and the course material?

4. Are there alternative digital representations of course content that are accessible and usable?

5. Are there options offered for student engagement with the course content and the course objectives through accessible e-learning tools (such as online mind mapping, discussion forums)?

6. Are there alternatives offered to students to demonstrate what they have learned through accessible ICTs [information and communication technologies] or e-learning tools (such as audio, visual, written, demonstration)?

7. Has the institution's access technologist been consulted as the e-learning and digital learning modules and activities are designed (to ensure that all aspects of the course structure and components are accessible and usable-for example, how readily and easily can the web site be navigated)?

Faculty, distance learning designers, and support staff should also be aware of accommodations that might be required if an online tool (e.g., the LMS or a third-party addition) is known to be inaccessible to certain students. For example, if a graphics-based writing "wall" or animated avatar application that is not accessible to students who are blind is used in a course, the instructor should consider not using the tool or providing alternatives for a student who is blind to gain the content that is a result of use of the tool (e.g., providing a transcript, summary) if they are enrolled in an offering of the course. A campus disability services office may be able to provide assistance in this regard.

Most studies of online learning do not address ac- cess issues for people with disabilities. Even studies about performance differences of student subgroups such as those defined by gender, age, and race, rarely explore differences between students with and without disabilities (e.g., Xu \& Jaggars, 2014).

UD can be applied to the overall design of a course, but it can also be built into an assignment. For example, in an online course taught by the author of this article,

small groups were assigned to complete a project and answer specific questions to report their work. The first thing they were told to do was decide which mode of communication they would employ so that all students could attend group "meetings" and fully engage in the collaboration. One group reported back that they used e-mail, at least in part, because one of the participants was deaf and could not easily engage using the synchronous communication modes offered. Actually, the majority of groups used asynchronous communication options, usually because this mode of communication, when compared to phone conferences and real-time chat sessions, worked best when group members lived in different time zones and/or had different daily schedules. Asynchronous communication also works well for individuals with slow input speeds. Even though one member disclosed her deafness, members of groups were not required to disclose disabilities or any other characteristics that contributed to their communication preference; they just needed to reach consensus on the communication tool they would use. In this course, if not for her voluntary disclosure, not even the instructor would have known she was deaf because the class was universally designed. For example, captions were provided on all video presentations. (Burgstahler, 2015a, p. 51)

Most faculty members do not address accessibility issues as they develop online courses. In one study, $80 \%$ of the respondents in a survey of online learning faculty had not considered the needs of students with disabilities and less than $12 \%$ had "partially" considered the needs of these students as they developed their courses (Bissonnette, 2006). Many instructors report that they are unaware of how to make their online courses accessible to students with disabilities (Gladhart, 2010; Roberts, Park, Brown, \& Cook, 2011). The combined results of three studies (Burgstahler, 2007) conclude that there is a need for accessibility training for online learning personnel and suggests that topics should include access challenges for people with disabilities, legal requirements, UD guidelines, specific design techniques and pedagogical strategies, and resources. Specific training for instructors, online course designers, and other stakeholder groups should be tailored to their needs. UD instruction should be integrat- 
ed into more general training offerings such as how to use the campus LMS.

Applying UD reduces the need for accommodations for students with disabilities. For example, captioning videos to be used in an online course means that students who are deaf will not require an accommodation to access the content. Captions may benefit other students as well. Through captions, students can see the spelling of words spoken in the presentation and search through the caption text for specific topics. Second language learners report that captions increase their attention, improve processing of vocabulary, and reinforce previous knowledge (Winke, Gass, \& Sydorenko, 2010). Several studies suggest the positive effects of captioning on recall and retention (Danan, 2004). Some evidence suggests that simultaneous text presentation along with audio can aid native and advanced nonnative speakers of English with word learning under certain conditions, as assessed by both explicit and implicit memory tests (Bird \& Williams, 2002). Such findings align with UD principles that recommend multimodal instruction. Although empirical research and anecdotal reports suggest the beneficial effect of captions, more data needs to be systematically collected to determine specific long-term benefits for students with various characteristics.

\section{Promising Approaches for Studying the UD of Online Learning and Its Widespread Practice}

Many researchers consider involvement of the student critical in designing online courses, but they differ in their views regarding how best to involve them and the level to which people with disabilities are routinely involved in the testing. Design methods that measure aspects of the social inclusion of students with a wide variety of characteristics hold promise for exploring the efficacy of UD with respect to online learning practices (Emiliani, 2009; Friedman, Kahn, Borning, \& Huldtgren, 2013). As summarized by Jane Seale in the United Kingdom:

We need new methodological approaches to "liberate" disabled students' voices; methods that offer us opportunities for critical self-reflection but also enable a dialogical relationship to be established with disabled students in which they are genuinely heard. (Seale, 2014b, p. 192)

Seale has explored complex interactions between students and technologies in online learning using a participatory design approach, where students are engaged in all steps of the research (e.g., Bjerknes \& Bratteteig, 1995; Seale, 2014b) and tests are made in real-life contexts and in iterative steps as the online learning design is improved.

Other design approaches that maximize the en- gagement of users include learner-centered design (Nesset $\&$ Large, 2004). In addition, value-sensitive design, a relatively new design approach which is grounded in the design of technology that accounts for human values within a cultural context (Friedman et al., 2013), addresses human values that include human welfare, privacy, freedom from bias, trust, autonomy, informed consent, identity, and courtesy. Steps in applying value-sensitive design may include identifying values, technology, and context; determining direct and indirect stakeholders; identifying potential benefits and harms for each stakeholder group; mapping benefits and harms onto corresponding values; identifying value conflicts; and integrating value considerations into the structure of the organization (Friedman et al., 2013).

The term usability is used to refer to the iterative testing and feedback process wherein users are observed as they interact with the product features. Usability issues addressed include ease of use, simplicity of learning, efficiency in performing tasks and addressing errors, memorability, and user satisfaction for all users (Nielson, 2012). The usability process is often employed multiple times during phases of product development in order to make the developing product more efficient and practical for customers. Usability testing practices hold promise for studying design practices that employ UD and thus maximize social inclusion in online courses when researchers engage participants with a broad range of abilities and disabilities in the usability tests (e.g., Horton, 2005; Schneiderman, 1999).

An example of a world wide effort that promotes the universal design of technology is the Global Public Inclusive Infrastructure (GPII), a project of Raising the Floor (2011). The purpose of the GPII is not to create new assistive technologies or services, but rather to create an infrastructure that makes their development and use easier, less expensive, and more effective. GPII leaders provide the following analogy:

Like building a road system does not provide transportation but greatly enhances the ability of car companies and others to do so-and provides an infrastructure that car companies themselves cannot do. The Internet is the infrastructure for general information and commerce. The GPII enhancements to the Internet would provide the infrastructure to enable the Internet to be truly inclusive for the first time. (Raising the Floor, n.d., p. 1)

The goal of GPII is to eliminate barriers to access and use of the Internet that are related to disability, literacy, technical expertise, aging, or financial resources. As countries build their broadband infrastructures to reach everyone, GPII leaders work to ensure that "everyone" includes people with a wide range of characteristics that include disability.

In spite of efforts by researchers and practitioners 
to promote universal/accessible design of online learning and the availability of guidelines and standards for the accessible design of technology and teaching strategies, evidence of widespread practice of the inclusive design of online courses does not exist. Besides general issues related to difficulties in making people aware of changes needed and integrating changes into existing practices, reasons for this situation may include that many content specialists who are charged with developing online courses have little guidance in creating effective online learning and little if any background in pedagogy and effective instructional design, including inclusive design practices. Even those charged with supporting the design of online courses may not have knowledge of strategies for reaching a broad audience and of IT accessibility issues. Therefore, few exemplar courses are available to faculty members and to those in course design and IT support roles. Based on interactions with individuals in these roles, the author of this article believes that few of them have learned of accessible/universal design practices in their own training process. In order for widespread adoption, there is a need to increase resources for online learning designers, faculty, IT support staff, and IT developers regarding legal requirements to offer accessible online courses, guidelines and standards available, and examples of successful practices. Further research is also needed to document the efficacy of specific universal design strategies overall and specifically for students with various types of disabilities.

\section{Conclusion}

The application of UD to online instruction holds promise for addressing the needs of a worldwide student body that is increasingly diverse with respect to race, ethnicity, culture, native language, age, learning style, background knowledge, gender, disability, and other characteristics. UD and similar terminology have emerged to describe approaches to inclusive design that has the potential to support social inclusion. In these approaches, instructors and course designers consider the needs of students with a broad range of characteristics as they develop flexible strategies that make instruction welcoming to, accessible to, usable by all students. Employing a UD process goes beyond ensuring accessibility for individuals with disabilities to address usability issues such as ease of use, efficiency, memorability, and user satisfaction for all users. Improving access and usability for people with disabilities also improves usability for others, thus creating a platform for the social inclusion of all students. It can be argued that it is simply good business practice for online course providers to avoid excluding large populations of consumers from effectively engaging in their courses.

\section{Acknowledgments}

This article is based on work supported by the National Science Foundation (grant number CNS-1042260 and number 1550477). Any opinions, findings, and conclusions or recommendations are those of the author and do not necessarily reflect the policy or views of the U.S. government, and you should not assume its endorsement.

\section{Conflict of Interests}

The author declares no conflict of interests.

\section{References}

Allen, I. E., \& Seaman, J. (2009). Learning on demand: Online education in the United States. Retrieved from http://www.sloanconsortium.org/publications/surve $\mathrm{y} / \mathrm{pdf} /$ learningondemand.pdf

Barnard-Brak, L., \& Sulak, T. (2010). Online versus faceto-face accommodations among college students with disabilities. The American Journal of Distance Education, 24, 81-91.

Berners-Lee, T. (n.d.). W3C Web accessibility initiative. Retrieved from http://www.w3.org/WAl

Bird, S. A., \& Williams, J. N. (2002). The effect of bimodal input on implicit and explicit memory: An investigation into the benefits of within-language subtitling. Applied Psycholinguistics, 23(4), 509-533.

Bissonnette, L. (2006). Meeting the evolving education needs of faculty in providing access for university students with disabilities. Retrieved from http:// spectrum.library.concordia.ca/8741

Bjerknes, G., \& Bratteteig, T. (1995). User participation and democracy: A discussion of Scandinavian research on system development. Scandinavian Journal of Information Systems, 7(1), 73-97.

British Standards Institute. (2010). BS 8872:2010 Web accessibility; Code of practice. Retrieved from http://shop-bsiggroup.com

Bruce, R. R., \& Wyman, S. (1998). Changing organizations: Practicing action training and research. Thousand Oaks: Sage Publications.

Burgstahler, S. (2002). Distance learning: Universal design, universal access. AACE Journal, 10(1), 32-61. Retrieved from http://www.editlib.org/index.cfm?fuse action=Reader.ViewAbstract\&paper_id=17776

Burgstahler, S. (2005). Web-based distance learning and the second digital divide. In M. Khosrow-Pour (Ed.), Encyclopedia of information science and information technology (pp. 3079-3084). Hershey, PA: Idea Group Inc.

Burgstahler, S. (2006). The development of accessibility indicators for distance learning programs. Association for Learning Technology Journal, 14(1), 79-102.

Burgstahler, S. (2007). Accessibility training for distance learning personnel. Access Technologists Higher Edu- 
cation Network (ATHEN) E-Journal, 2. Retrieved from http://athenpro.org/node/56

Burgstahler, S. (2012). Equal access: Universal design of distance learning programs. University of Washington Website. Retrieved from http://www.uw.edu/ doit/equal-access-universal-design-distance-learning -programs

Burgstahler, S. (2015a). Universal design of instruction. In S. Burgstahler (Ed.), Universal design in higher education: From principles to practice (pp. 31-64). Cambridge, MA: Harvard Education Press.

Burgstahler, S. (2015b). Universal design of technology. In S. Burgstahler (Ed.), Universal design in higher education: From principles to practice (pp. 231-251). Cambridge, MA: Harvard Education Press.

Burgstahler, S., Corrigan, B., \& McCarter, J. (2004). Making distance learning courses accessible to students and instructors with disabilities: A case study. Internet and Higher Education, 7, 233-246.

Burgstahler, S., Corrigan, B., \& McCarter, J. (2005). Steps toward making distance learning accessible to students and instructors with disabilities. Journal of Information Technology and Disabilities, 11(1). Retrieved from http://www.rit.edu/ easi/itd/itdv11n1/ brgstler.htm

Center for Universal Design (CUD). (1997). The principles of universal design, version 2.0. North Caroline State University Website. Retrieved from http://www. ncsu.edu/ncsu/design/cud/about_ud/udprincipleste xt.htm

Closing the Gap. (2015). Closing the Gap solutions. Closing the Gap. Retrieved from http://www.closingthe gap.com/solutions/search

Coombs, N. (2010). Making online teaching accessible: Inclusive course design for students with disabilities. San Francisco: Jossey-Bass.

Danan, M. (2004). Captioning and subtitling: Undervalued language learning strategies. Meta: Journal des traducteurs/Meta: Translators' Journal, 49(1), 67-77.

DO-IT (n.d.-a). The Center for Universal Design in Education. University of Washington Website. Retrieved from http://www.washington.edu/doit/programs/ center-universal-design-education/overview

DO-IT. (n.d.-b). How can I get started in making my distance learning course accessible to all students? University of Washington Website. Retrieved from http://www.uw.edu/doit/how-can-i-get-startedmaking-my-distance-learning-course-accessible-allstudents

DO-IT. (n.d.-c). AccessDL. University of Washington Website. Retrieved from http://www.uw.edu/doit/Res ources/accessdl.html

Donnelly, P., \& Coakley, J. (2002). The role of recreation in promoting social inclusion. Toronto, ON: Laidlaw Foundation.

Emiliani, P. L. (2009). Perspectives on accessibility: From assistive technologies to universal access and design for all. In C. Stephanidis (Ed.), Universal access handbook (pp. 2.1-2.18). Boca Raton, FL: CRC Press.

Fichten, C. S., Ferraro, V., Asuncion, J. V., Chwojka, C., Barile, M., Nguyen, M. N., Klomp, R., \& Wolforth, J. (2009). Disabilities and e-learning problems and solutions: An exploratory study. Educational Technology and Society, 12(4), 241-256.

Friedman, B., Kahn, Jr., P. H., Borning, A., \& Huldtgren, A. (2013). Value sensitive design and information systems. In N. Doorn, D. Schuurbiers, I. van de Poel, \& M. E. Gorman (Eds.), Early engagement and new technologies: Opening up the laboratory (pp. 55-95). Dordrecht, The Netherlands: Springer Netherlands.

Gladhart, M. A. (2010). Determining faculty needs for delivering accessible electronically delivered instruction in higher education. Journal of Postsecondary Education and Disability, 22(3), 185-196.

Gurin, P., Dey, E. L., Hurtado, S., \& Gurin, G. (2002). Diversity and higher education: Theory and impact on educational outcomes. Harvard Educational Review, 72(3), 330-366.

Guy, T. C., Reiff, J. C., \& Oliver, J. P. (1998). Infusing multicultural education: A process of creating organizational change at the college level. Innovative Higher Education, 22(4), 271-289.

Heiman, T. (2008). Females with learning disabilities taking on-line courses: Perceptions of the learning environments, coping and well-being. Journal of Postsecondary Education and Disability, 21(1), 4-14.

Horton, S. (2005). Access by design. San Francisco: New Riders Press.

International Association for $\mathrm{K}-12$ Online Learning. (2011). Version two national standards for quality online courses. Vienna, VA: International Association for $\mathrm{K}-12$ Online Learning.

Keeler, C. G., \& Horney, M. (2007). Online course designs: Are special needs being met? American Journal of Distance Education, 21(2), 61-75.

Kim-Rupnow, W. S., Dowrick, P. W., \& Burke, L. S. (2001). Implications for improving access and outcomes for individuals with disabilities in postsecondary distance education. American Journal of Distance Education, 15(1), 37-41.

Kinash, S., Crichton, S., \& Kim-Rupnow, W. S. (2004). A review of 2000-2003 literature at the intersection of online learning and disability. American Journal of Distance Education, 18(1), 5-19.

National Council on Disability. (2004). Design for inclusion: Creating a new marketplace. National Council on Disability Website. Retrieved from http://www. ncd.gov/newsroom/publications/2004/online_newm arketplace.htm

Nesset, V., \& Large, A. (2004). Children in the information technology design process: A review of theories and their applications. Library and Information Science Research, 26, 140-161.

Nielsen, J. (2012). Usability 101: Introduction to usability. 
Nielsen Norman Group. Retrieved from http:// www.nngroup.com/articles/usability-101-introduct ion-to-usability

Pearson, E., \& Koppi, T. (2006). Supporting staff in developing inclusive online learning. In M. Adams \& S. Brown (Eds.), Towards inclusive teaching in higher education (pp. 56-66). London: Routledge.

Phillips, A., Terras, K., Swinney, C., \& Schneweis, C. (2013). Online disability accommodations: Faculty experiences at one public university. Journal of Postsecondary Education and Disability, 25(4), 346-366. Retrieved from http://www.ahead.org/publications/ jped/vol_25

Quality Matters. (n.d.). Higher Ed Program: Rubric. Retrieved from https://www.qualitymatters.org/rubric

Raising the Floor. (2011). GPII. Retrieved from http:// gpii.net

Rangin, H. (2011). How to guide for creating accessible online learning. CANnect. Retrieved from http:// projectone.cannect.org

Roberts, J. B., Crittenden, L. A., \& Crittenden, J. C. (2011). Students with disabilities and online learning: A cross-institutional study of perceived satisfaction with accessibility compliances and services. Internet and Higher Education, 14(4), 242-250.

Roberts, K. D., Park, H. J., Brown, S., \& Cook, B. (2011). Universal design for instruction in postsecondary education: A systematic review of empirically based articles. Journal of Postsecondary Education and Disability, 24(1), 5-15.

Savidis, A. \& Stephanidis, C. (2005). Developing inclusive e-learning and e-entertainment to effectively accommodate learning difficulties. SIGACCESS Accessibility and Computing, 83, 42-54.

Schneiderman, B. (1999). Universal usability: Pushing human-computer interaction research to empower every citizen. ISR Technical Report 99-72. College Park: University of Maryland, Institute for Systems Research.

Seale, J. K. (2014a). E-learning and disability in higher education: Accessibility research and practice. Lon- don: Routledge, Taylor \& Francis.

Seale, J. K. (2014b). Re-imagining accessibility research: Methods to enable a democratic voice to be heard. In E-learning and disability in higher education: Accessibility research and practice (2nd ed., pp. 192214). Abingdon, UK: Routledge Taylor \& Francis Group.

Silver, P., Bourke, A., \& Strehorn, K. C. (1998). Universal Instructional Design in higher education: An approach for inclusion. Equity \& Excellence, 31(2), 4751.

Thomson, R., Fichten, C. S., Havel, A., Budd, J., \& Asuncion, J. (2015). Blending universal design, e-learning, and information and communication technologies. In S. Burgstahler (Ed.), Universal design in higher education: From principles to practice (pp. 275-284). Cambridge, MA: Harvard Education Press.

United Nations. (2006). Convention on the rights of persons with disabilities. Retrieved from http://www.un. org/esa/socdev/enable/rights/convtexte.htm\#convt ext

Web Accessibility Initiative (WAI). (n.d.-a). How to meet WCAG 2.0. Retrieved from http://www.w3.org/WAl/ WCAG20/quickref

WAI. (n.d.-b). Introduction to understanding WCAG 2.0. Retrieved from http://www.w3.org/TR/UNDERSTAN DING-WCAG20/intro.html

WAI. (n.d.-c). Introduction to web accessibility. Retrieved from https://www.w3.org/WAl/intro/accessibility.php

Winke, S., Gass, S, \& Sydorenko, T. (2010). The effects of captioning videos used for foreign language listening activities. Language Learning \& Technology, 14(1), 65-86.

World Wide Web Consortium (W3C). (2003). Web content accessibility guidelines 2.0: W3C working draft 24 June 2003. Retrieved from http://www.w3.org/tr/ 2003/wd-wcag20-20030624

Xu, D., \& Jaggars, S. S. (2014). Performance gaps between online and face-to-face courses: Differences across types of students and academic subject areas. Journal of Higher Education, 85(5), 633-659.

\section{About the Author}

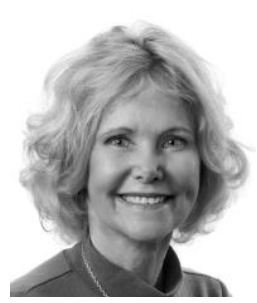

\section{Dr. Sheryl Burgstahler}

Sheryl Burgstahler, Ph. D., is the Director of Accessible Technology Services within UW-IT and an Affiliate Professor in the College of Education at the University of Washington in the USA, Much of her work focuses on the transition to college and careers for students with disabilities and the universal design of instruction, student services, physical spaces, and technology. 